\title{
LOMBER DISK HERNIASYONUNU TAKLIT EDEN EOZINOFILIK GRANULOM: OLGUSU SUNUMU
}

\author{
Erkan Kaptanoğlu* * Özerk Okutan* \&event Albayrak** * Etem Beşkonaklı*
}

\begin{abstract}
ÖZET
Erişkinlerde omurganın eozinofilik granulomu çok nadirdir. Hastalık hemen daima omurganın korpusunu tutar ve literatürde disk mesafesine sınırlı lezyonu olan vaka bildirilmemiştir. Yazarlar kök basısı nedeni ile başvuran 42 yaşındaki erkek hastada, L5-S1 disk mesafesinin eozinofilik granulomu olan nadir vakayı sunmuşlardır. 6 aylık bel ve bacak ağrısını takiben çekilen manyetik rezonans (MR) görüntüleme, L5-S1 disk protrüzyonunu göstermiştir. Hasta lomber disk hernisi ön tanısı ile opere edilmiş ve daha sonra lezyonun, disk mesafesinin eozinofilik granulomu olduğu gösterilmiştir.
\end{abstract}

Anahtar Kelimeler: Eozinofilik Granulom, Omurga, Manyetik Rezonans Görüntüleme

Eozinofilik granulom, Langerhans hücreli histiositozisin bir alt tipi olup, kendini soliter kemik lezyonu ile gösteren sınırlı ve iyi huylu bir tümördür. Dokuda mononuklear hücre ve eozinofil infiltrasyonu ile karakterizedir (1). Genellikle 10 yaş altındaki çocuklarda görülür ve olguların \% 715 'inde vertebra tutulumu vardır $(2,3)$. Vertebra korpusunun destrüksiyonuna bağlı şiddetli ağrı oluşur, nörolojik bulgu görülmesi nadirdir (4). Vertebra plana, hastalığın vertebra tutulumu olduğunda beklenen klasik radyolojik bulgusudur. Ayırıcı tanıda akut lösemi, anevrizmal kemik kisti, metastatik nöroblastoma ve Ewing sarkomu akılda tutulmalıdır. Vertebra plananın osteomyelitte de görülebileceği bildirilmiştir (5). Tedavide genel yaklaşım nörolojik defisiti olan hastalara cerrahi uygulanması olmakla birlikte, radyasyon ve stero-

\begin{tabular}{l} 
SUMMARY \\
Eosinophilic Granuloma Mimicking Lumbar \\
Disk Herniation: A Case Report \\
Adult cases of eosinophilic granuloma of the vertebrae is \\
very rare. The disease almost always affect the vertebral \\
bodies and there is no case report in which then disease \\
is limited to intervertebral disc space in the literature. \\
Authors presented an unusual case of eosinophilic granu- \\
loma of L5-S1 disc in a 42 year old man who presented \\
with root compression. After 6 months of low back and \\
leg pain, magnetic resonans imaging (MRI) demonstrated \\
L5-S1 disk protrusion. Patient was operated on the diag- \\
nosis of lumbar disk disease. The lesion was later con- \\
firmed to be an eosinophilic granuloma of the disk \\
space. \\
Key Words: Eosinophilic Granuloma, Vertebra, \\
Magnetic Resonance Imaging \\
\hline
\end{tabular}

id tedavisinin de olumlu sonuçlar gösterebileceği bildirilmiştir (6).

Yazımızda lomber disk aralığından posteriora uzanım göstererek sinir kökü basısına neden olan eozinofilik granulom olgusu, manyetik rezonans (MR) görüntüleri ile tartışılmıştır.

\section{Olgu Sunumu:}

42 yaşında erkek hasta, 6 aydır mevcut olan bel ve sol bacak ağrısı nedeniyle kliniğimize başvurdu. İdrar ve gaita inkontinansı tariflemiyordu. Yapılan nörolojik muayenesinde düz bacak germe testi solda 45 derecede pozitif idi. Sol ayak eversiyon ve plantar fleksiyonunda kuvvet kaybı ile sol sakral 1 kökü dermatomuna uyan his kaybı mevcuttu. Sol aşil refleksi azalmıştı. Patolojik refleks yoktu. Lomber manyetik rezonans görüntülemede

\footnotetext{
* Ankara Numune Eğitim ve Araştırma Hastanesi, 1. Nöroşirurji Kliniği

** Ankara Numune Eğitim ve Araştırma Hastanesi, Patoloji Kliniği
} 
(MRG) sagittal T1 kesitlerde L5-S1 disk mesafesi posteriorunda beyin omurilik sıvısına göre hiperintens, düzensiz ekstrude disk hernisi ile uyumlu olabilecek görünüm mevcuttu. Sagittal T2 kesitlerde, L5-S1 disk mesafesinin hipointens (siyah disk) görünümü ve posteriorda dural saka doğru protruzyonu dikkati çekmekte idi. Aksiyal kesitlerde, dural sakın sol anteriordan posteriora doğru basılı olduğu görülmekte idi (Şekil 1,2,3).

Hasta bu bulgularla lomber disk hernisi ön tanısı ile opere edildi. Operasyonda L5-S1 disk mesafesi posteriorunda hemorajik, multilobule tümöral kitle ile karşılaşıldı. Tümörün kemik yada dura invazyonu yapmadı̆̆ı, disk mesafesinden posteriora doğru protrüde olarak sınırlı kaldığı görüldü. Tümör gros-total olarak çıkarılarak patolojik değerlendirme yapıldı.

Patolojik örneklerde fibroz bağ dokusu içerisinde lenfosit, plazma hücreleri ve arada eozinofilik lenfositlerin varlığı görülmekte idi. Bu yapı içersinde ayrıca multinükleer hücreler ve lobule nukleuslu nukleer çentiklenmeler gösteren histiositler saptanmakta idi. Bu bulgularla hastaya eozinofilik granulom tanısı konuldu ( Şekil 4,5 ).

\section{Tartışma:}

Erişkin populasyonunda vertebranın eozinofilik granulomu nadirdir. Hastaların başvuru şika-

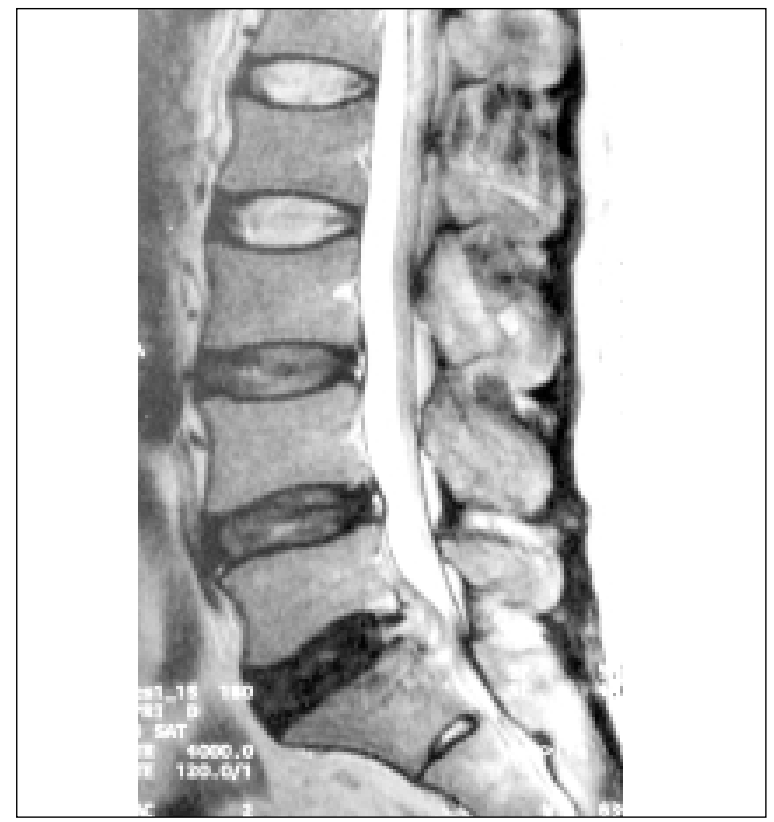

Şekil 1: Lomber MR görüntüleme, sagittal T2 kesitleri. L5-S1 disk aralığında posteriora doğru protrüde olmuş, disk aralı̆̆ı ile devamlılı̆̆ı olan eozinofilik granulom. yetleri, nörolojik defisit olsun yada olmasın, öncelikle ağrıdır. Asıl yerleşim yeri vertebra korpusu olan eozinofilik granulomun tipik radyolojik bulguları arasında osteolitik defektler, sklerotik reaksiyon ve vertebra korpusunda çökme sayılabilir

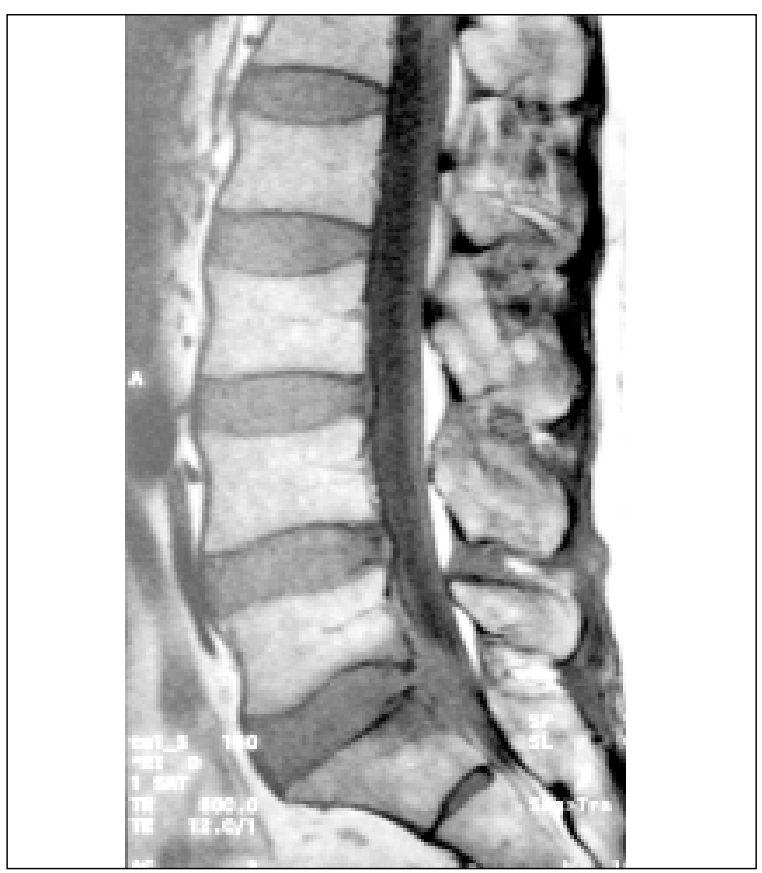

Şekil 2: Lomber MR görüntüleme, sagittal T1 kesitleri. L5-S1 disk aralığında posteriora doğru protrüde olmuş, sınırları oldukça düzensiz görülen eozinofilik granulom.

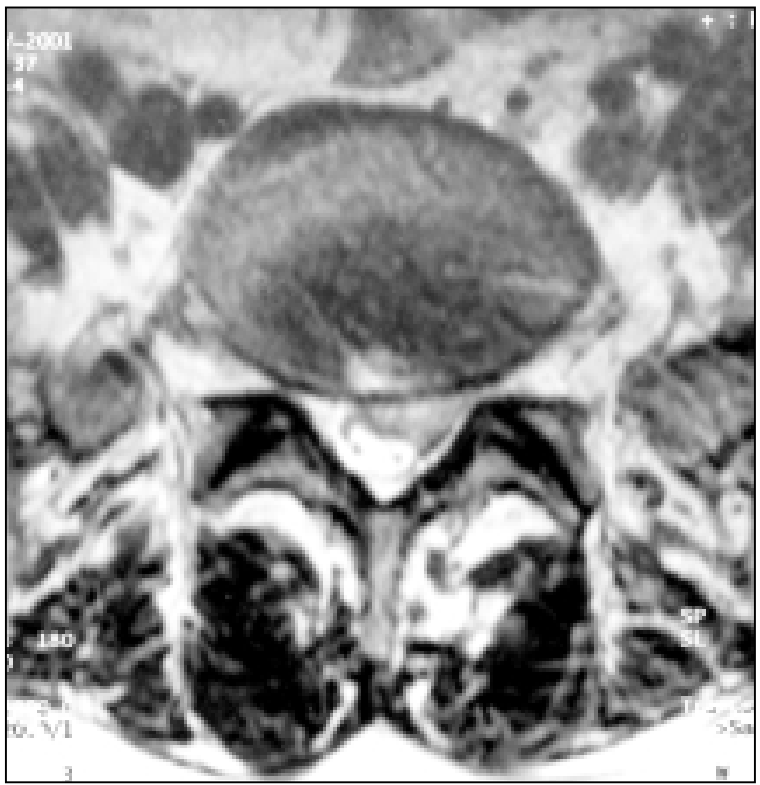

Şekil 3: Lomber MR görüntüleme, aksiyal T2 kesitleri. L5-S1 disk aralığında posteriora doğru protrüde olmuş, spinal kanal sol ön yarısını oblitere etmiş ve durayı posteriora doğru itmiş eozinofilik granulom. 


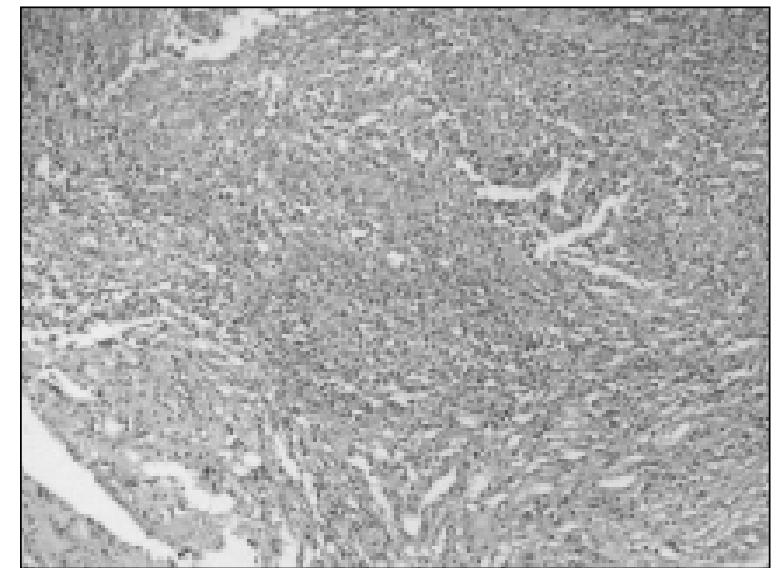

Şekil 4: Lezyonun histopatolojik görünümü. Lenfoplazmositer hücre infiltrasyonu ve arada histiositler, multinükleer hücreler gözlenmekte (H.E.X100).

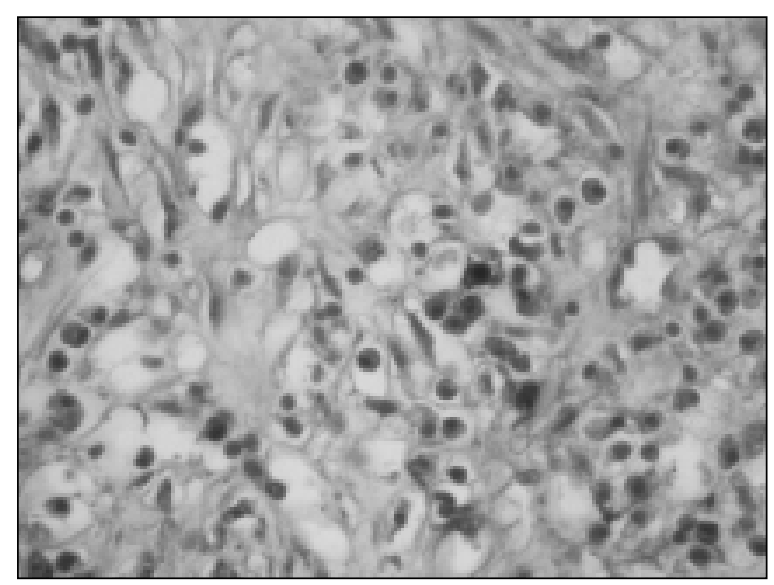

Şekil 5: Lezyonun histopatolojik görünümü. Lenfoplazmositer hücre infiltrasyonu arasında S-100 pozitif histiositik hücreler görülmektedir (S-100X400).

(7). Nörolojik hasar vertebra korpusunun çökmesi yada hastalığın epidural aralığa yayılması neticesinde omuriliğe bası ile oluşmaktadır. Sunulan vakada vertebra korpus tutulumu saptanmamış, hastalık disk aralığında sınırlı kalmıştır.

Bu olguda disk aralığını tutan eozinofilik granulom tanısı preoperatif düşünülmemiştir. Vertebranın eozinofilik granulomunu düşündürecek spesifik klinik bulgu bulunmamaktadır. Tanı, operasyon sırasında alınan patoloji örneği ile konulmuştur. Hastanın preoperatif MR görüntüleri değerlendirildiğinde de disk aralığının eozinofilik granulomundan şüphelenilmemiştir. Eozinofilik granulom bu lokalizasyonda literatürde daha önce hiç bildirilmediği için radyolojik bulguları da bilinmemek- tedir. Vertebranın eozinofilik granulomunda radyolojik olarak görülen osteolitik lezyonlar, vertebra kollapsı yada nadiren görülen ekspanse lezyonlar, bu olguda yoktur $(7,8)$. Hastanın MR görüntüleri retrospektif olarak tekrar incelendiğinde ekstrude disk hastalığı düşünülen mesafenin diskinin T2 ağırlıklı görüntülerde tamamen siyahlaşmış olduğu ve posteriora uzanan lezyonun disk aralığı ile devamlılık gösterdiği dikkat çekmektedir. Bu bulgu dejenere ve ekstrude disk hernisi lehinedir. T1 ağırlıklı kesitlerde gözlenen posterior herniasyon birçok disk herniasyonunda gördügümüz bulgudur. Posteriora uzanan lezyonun disk hernisi olmadığını düşündürebilecek tek bulgu L5-S1 disk mesafesinin çökmemiş olmasıdır (Şekil 1,2,3).

Eozinofilik granulomun tedavi edilmediği taktirde doğal seyrini gösteren çalışmalar yoktur ve değişik klinik seyri olabileceği için tedavi yaklaşımları konusunda standardizasyon oluşturulamamıştır. Vertebral eozinofilik granulomun tedavisinde immobilizasyon, radyoterapi, kemoterapi, defektif vertebranın kürete edilmesi ve kemik greft yerleştirilmesi uygulanmakta ve iyi sonuçlar alınmaktadır (9). Sunulan olgu nörolojik defisite neden olduğundan, cerrahi tedavi için uygun bir aday olduğu inancındayız. Ancak disk mesafesinde eozinofilik granulomu olan bir hastaya operasyon öncesi tanı konma şansı olsa dahi, en iyi tedavinin ne olacağı konusunda bizim tecrübemiz olmadığı gibi, literatürde de bu lokalizasyonda bildirilmiş hasta yoktur.

Islinger ve ark.'ı spinal tutulumun çocuklarda \% 10 oranında görüldüğünü, bu oranın erişkinlerde \% 3 olduğunu bildirmişlerdir (10). Hastalık daha çok erkeklerde görülmekte ve erişkinlerdeki lezyonların hemen hepsi torakal vertebralarda gözlenmektedir. Sunulan olguda eozinofilik granulomun erişkinde ve lomber bölgede görülmesi, literatürdeki vertebra eozinofilik granulom vakalarında da son derece nadir olarak bildirilmiştir. Lezyonun vertebra disk aralığına sınırlı kalması literatürde bildirilen ilk vakadır.

Sonuç olarak, vertebranın eozinofilik granulomu lomber disk mesafesine lokalize olduğu taktirde, lomber disk hastalığını taklit edebilmektedir. Vertebra eozinofilik granulomunun ayırıcı tanısında disk herniasyonları da akla gelmelidir. 


\section{KAYNAKLAR}

1. Çaylı SR, Beşkonaklı E, Soylu U, Yalçınlar Y: Kranial eozinofilik granuloma: Iki olgu sunumu. Ankara Numune Hastanesi Tıp Dergisi 1996; 36:118-121.

2. Villas C, Martinez-Peric R, Borris RH: Eosinophilic granuloma of the spine with or without vertebra plana: longterm follow-up of six cases. J Spinal Disord 1993; 6:260-268.

3. Wroble RR, Weinstein SL: Histiocytosis X with scoliosis and osteolysis. J Pediatr Orthop 1988; 8:213218.

4. Yabsley RH, Harris WR: Solitary eosinophilic granuloma of vertebral body causing paraplegia. J Bone Joint Surg (Am) 1966; 48A:1570-1574.

5. Yu L, Kassler JR, O'Rourke E, Kozakewich H: Chronic recurrent osteomyelitis: associated with vertebra plana. J Bone Joint Surg (Am) 1989; 71A:105-112.

6. Haggstrom JA, Brown JC, Marsh PW: Eosinophilic granuloma of the spine: MR demonstration. J Comput Assist Tomogr 1988; 12:344-345.
7. Sanchez RL, Lovet J, Monero A, Galito E: Symptomatic eosinophilic granuloma of the spine: Report of two cases and review of the literature. Ortophedics $1984 ; 7: 1721-1726$.

8. Silberstein MJ, Sundaram M, Akbarnia B, Luisiri A, McGuire M: Eosinophilic granuloma of the spine: Radiologic case study. Ortophedics 1985; 8:267274.

9. Kamimura $M$, Kinoshita $T$, Itoh $H$, Yuzawa $Y$, takahashi J, Ohtsuka K: Eosinophilic granuloma of the spine: early spontaneous disapperance of tumor detected on magnetic resonance imaging. Case report. J Neurosurgery (Spine 2) 2000; 93:312-316.

10. Islinger RB, Kuklo TR, Owens BD, Horan PJ, Choma TJ, Murphey MD, Temple T: Langerhans' cell histiosis in patients older than 21 years. Clin Ortop Relat $\operatorname{Res} 1989 ; 379: 231-235$. 